\title{
Implementasi Model CCR Data Envelopment Analysis (DEA) Pada Pengukuran Efisiensi Keuangan Daerah
}

\author{
LM. Fajar Israwan ${ }^{\mathrm{a}^{*}}$, Bayu Surarso ${ }^{\mathrm{b}}$, Farikhin $^{\mathrm{c}}$ \\ a Fakultas Teknik, Universitas Dayanu Ikhsanuddin \\ ${ }^{\mathrm{b}}$ Fakultas Sains dan Matematika, Universitas Diponegoro \\ ${ }^{\mathrm{c}}$ Fakultas Sains dan Matematika, Universitas Diponegoro
}

Naskah Diterima : 11 Maret 2016; Diterima Publikasi : 23 April 2016

DOI: $10.21456 /$ vol6iss1pp76-83

\begin{abstract}
Regional budget control system is implemented through an audit and evaluation to ensure that its implementation is in accordance with the plan that it can be efficiently and effectively used. Regional budget efficiency measurement then aims to measure the efficienty of budget use of each Regional Work Unit (SKPD) and to optimalize its use. The efficiency of Regional Work Unit is measured using CCR Data Envelopment Analysis (DEA) model with one input variable and eight output variables, in which this CCR DEA applies Linear Programming approach and evaluates relative efficiency of Decision Making Units (DMUs). The sample was in a total of sixteen DMUs. The result revealed that seven DMUs were efficient, in which their reference set was then used to optimalize the input and output variables of other inefficient DMUs. This result was validated through paired sample t-test, proving to meet the hypothesis of Ho $-2,042 \leq$ tcount $\leq 2,042$ showing that CCR DEA can be used as a method to measure regional budget efficiency with accurate results.
\end{abstract}

Keywords : CCR, DEA, Regional Financial, SKPD.

\begin{abstract}
Abstrak
Sistem pengendalian keuangan daerah dilakukan melalui audit dan evaluasi untuk menjamin pelaksanaan anggaran yang sesuai rencana agar dapat digunakan secara efisien dan efektif. Pengukuran efisiensi keuangan daerah bertujuan mengukur efisiensi penggunaan anggaran dari Satuan Kerja Perangkat Daerah (SKPD) sekaligus mengoptimalisasi penggunaan anggaran. Efisiensi SKPD dihitung menggunakan model CCR Data Envelopment Analysis (DEA) dengan satu variabel input dan delapan variable output. CCR DEA menggunakan Linear programming untuk mengevaluasi efisiensi relatif Unit Pembuat Keputusan. Total sampel yang digunakan adalah enam belas DMU. Hasil perhitungan menunjukkan bahwa tujuh DMU menggunakan anggaran secara efisien. Reference set dari tujuh DMU efisien selanjutnya digunakan untuk mengoptimalisasi variable input dan output DMU yang tidak efisien. Hasil perhitungan divalidasi menggunakan uji t sampel berpasangan, dan memenuhi hipotesis Ho $-2,042 \leq$ thitung $\leq 2,042$, menunjukkan bahwa CCR DEA dapat digunakan sebagai metode pengukuran efisiensi keuangan daerah dengan hasil yang akurat.
\end{abstract}

Kata Kunci : CCR, DEA, Keuangan Daerah, SKPD.

\section{Pendahuluan}

Permasalahan keuangan pemerintah berupa pendapatan, belanja dan kelebihan belanja diatas pendapatan (surplus) merupakan bagian dari masalah pembiayaan. Penanganan masalah pembiayaan ini tercermin dalam bentuk perencanaan anggaran. (Halim., 2014). Sistem pengendalian keuangan daerah sebagai suatu proses berkesinambungan, dilaksanakan oleh badan atau unit yang mempunyai tugas dan fungsi melakukan pengendalian melalui audit dan evaluasi serta menjamin agar pelaksanaan kebijakan pengelolaan

*) Penulis korespondensi: fajar.publisher@gmail.com keuangan daerah sesuai dengan rencana. Aturan tersebut dimaksudkan agar efisiensi dan efektifitas penggunaan anggaran tetap terjaga (PP 58, 2005).

Metode dalam pengukuran efisiensi dapat dilakukan dengan pendekatan nonparametik yang tidak stokastik, berdasarkan penemuan dan observasi dari populasi dan mengevaluasi efisiensi relatif terhadap unit-unit yang diobservasi. Pendekatan ini dikenal dengan nama Data Envelopment Analysis (DEA) (Rusydina., 2013). DEA biasanya digunakan untuk teori produksi dalam Ilmu Ekonomi, selain itu digunakan pula untuk benchmarking (tolak ukur) dalam manajemen operasi untuk menghasilkan 
Decision Making Unit (DMU) / Unit Pengambil Keputusan (UPK) yang efisien (Zhu., 2014).

Penelitian tentang pengukuran efisiensi telah banyak dilakukan baik pada sektor bisnis maupun sektor publik. Penelitian untuk menganalisis efisiensi pelaksanaan anggaran belanja Badan Perencanaa Pembangunan Daerah (BAPPEDA) Minahasa Selatan menggunakan analisis deskriptif, data yang digunakan yaitu anggaran belanja tahun 2008 - 2012. Tingkat efisiensi diukur dengan cara membandingakan realisasi anggaran belanja langsung dengan total realisasi anggaran belanja (Sumenge., 2013).

Penelitian dengan tujuan menyajikan data empiris mengenai efisiensi Bank Islam di negara-negara Timur Tengah dan tujuh negara Asia selama krisis keuangan. Hasil penelitian ini menunjukan sumber utama inefisiensi teknis adalah karena bank syariah yang beroperasi diskala yang salah, terutama karena Bank Syariah di Timur Tengah beroperasi pada Decreasing Return to Scale (DRS). Sehingga perlu mengurangi input untuk mencapai skala optimal (Rosman et al., 2014).

Penelitian pada Devisi Wire Rod Mill disuatu perusahaan. Penelitian ini bertujuan untuk menerapakan model CCR dan BCC DEA dengan orientasi output untuk mengetahui kinerja produksi dan faktor-faktor yang berpengaruh terhadap efisiensi produksi. Hasil penelitian menunjukan faktor dengan nilai bobot terbesar memiliki pengaruh yang besar terhadap peningkatan kinerja perusahaan, sedangkan faktor dengan nilai bobot kecil memiliki pengaruh yang kecil pula terhadap peningkatan kinerja perusahaan. Untuk meningkatkan efisiensi produksi, perusahaan harus meningkatkan produksinya sesuai dengan kapasitas yang tersedia agar sumber daya yang digunakan teralokasi dengan optimal. (Utama., 2013).

Penelitian yang dilakukan menggunakan Model CCR DEA dengan karakterisitik single input dan multiple output, dengan objek Keungan Daerah. Penelitian ini mengukur sejauhmana efisiensi penggunaan keuangan daerah dan mengoptimalisasi penggunaan keuangan daerah. Hasil dari perhitungan CCR DEA ditampilkan dalam bentuk dashboard berupa nilai efiseinsi penggunaan keuangan dari tiap SKPD, grafik efsiensi dan rekomendasi anggaran dari hasil optimalisasi nilai input dan output.

\section{Kerangka Teori}

\subsection{Efsiensi}

Efisiensi mempunyai pengertian perbandingan antara keluaran (output) dan masukan (input) (Syamsu., 2007). Sebuah sistem yang lebih efisien memperoleh lebih banyak output untuk satu set input sumber daya, atau mencapai tingkat yang sebanding output untuk input yang lebih sedikit (Hanushek., 1994).
Salah satu metode yang dapat digunakan dalam pengukuran efisiensi yaitu melalui pendekatan frontier. Terdapat dua jenis dalam pendekatan ini, yaitu:

1. Pendekatan frontier parametik, merupakan pendekatan yang modelnya menetapakan adanya syarat-syarat tertentu pada parameter populasi yang menjadi sumber penelitian. Pendekatan frontier parametik dapat diukur denggan tes statistik menggunakan Metode Stochastic Frontier Analysis (SFA) dan Distribution Free Analysis (DFA).

2. Pendekatan frontier non parametik, yaitu pendekatan yang tidak menetapkan syarat tertentu pada parameter populasi sampel penelitian. pendekatan frontier non parametrik dapat diukur dengan menggunakan Metode Data Envelopment Analysis (DEA).

\subsection{Keuangan Daerah}

Pasal 64 ayat (2) UU Nomor 5 Tahun 1974 tentang Pokok-Pokok Pemerintahan Daerah, APBD didefinisikan sebagai rencana operasional keuangan pemerintah daerah yang menggambarkan pengeluaran guna pembiayaan kegiatan-kegiatan dan proyek-proyek dalam satu tahun anggaran tertentu. Pendekatan yang dipakai dalam penyusuana anggaran adalah pendekatan line-item (pendekatan tradisional), dimana anggaran disusun berdasarkan jenis penerimaan dan pengeluaran dengan tujuan mengendalikan setiap pengeluaran yang dilakukan (Halim., 2007).

\subsection{Data Envelopment Analysis (DEA)}

Data Envelopment Analysis atau disingkat DEA pertama kali diperkenalkan pada tahun 1978 oleh Charnes A, Cooper WW dan Rhodes E dalam jurnal Operational Research dengan judul "Measuring The Efficiency of Decision Making Units". Jurnal tersebut membahas pengembangan langkah-langkah pengambilan keputusan efisiensi yang dapat digunakan dalam mengevaluasi Unit Pengambil Keputusan (Charnes et al., 1978).

DEA adalah teknik berbasis pemrograman linear untuk mengevaluasi efisiensi relatif dari unit pengambilan keputusan, dengan cara membandingkan antara DMU satu dengan DMU lain yang memanfaatkan sumber daya yang sama untuk menghasilkan output yang sama (Tsai et al., 2002), dimana solusi dari model tersebut mengindikasikan produktifitas atau efisiensi suatu unit dengan unit lainnya (Taylor., 2014). Tujuan akhir dari DEA dimaksudkan sebagai metode untuk evaluasi kinerja dan benchmarking (Zhu et al., 2014).

Efisiensi relatif dari DMU diukur dengan memperkirakan rasio bobot output untuk suatu input dan membandingkannya dengan DMU lainnya. DMU yang mencapai efisensi $100 \%$ dianggap efsien sedangkan DMU dengan nilai dibawah $100 \%$ 
dianggap tidak efisien. DEA mengidentifikasi satu set DMU yang efesien dan digunakan sebagai tolak ukur untuk perbaikan DMU yang tidak efisien. DEA juga memungkinkan melakukan perhitungan jumlah yang diperlukan untuk perbaikan dalam input dan output pada DMU sehinggan menjadi efisien (Lee et al., 2012).

Ukuran dasar efisiensi yang digunakan dalam DEA adalah rasio total output total input.

$$
\text { Efficiency }=\frac{\text { Output }}{\text { Input }}
$$

Simbol dalam formulasinya diggunakan $x$ dan $y$ untuk mewakili input dan output, $i$ dan $j$ untuk mewakili input dan output tertentu. Sehingga $x_{\mathrm{i}}$ merupakan input ke- $i$ dan $y_{\mathrm{j}}$ merupakan output ke- $j$ pada unit pengambil keputusan / DMU. Jumlah dari input diwakili $I$ dan jumlah dari output diwakili $J$, dimana $I, J>0$. Secara matematis dapat digambarkan sebagai berikut (Ramanathan., 2003):

$$
\text { Virtual Input }=\sum_{i=1}^{I} \boldsymbol{u}_{i} \boldsymbol{x}_{i}
$$

Dengan $u_{\mathrm{i}}$ adalah bobot dari input $x_{\mathrm{i}}$ selama proses akumulasi. Untuk output dapat digambarkan sebagai berikut:

$$
\text { Virtual Output }=\sum_{j=1}^{J} v_{j} y_{j}
$$

Dengan $v_{\mathrm{j}}$ adalah bobot dari input $y_{\mathrm{j}}$ selama proses akumulasi. Dari model virtual input dan output diatas, maka efisiensi dapat didefinisikan sebagai berikut :

$$
\text { Efficiency }=\frac{\text { Virtual Output }}{\text { Virtual Input }}=\frac{\sum_{j=1}^{J} v_{j} y_{j}}{\sum_{i=1}^{I} u_{i} x_{i}}
$$

Jika ada $N$ DMU yang akan dibandingkan tingkat efisiensinya, maka bentuk pecahan linear program DEA adalah sebagai berikut:

$$
\max E_{m}=\frac{\sum_{j=1}^{J} v_{j m} y_{j m}}{\sum_{i=1}^{I} \boldsymbol{u}_{i m} \boldsymbol{x}_{i m}}
$$

Subject to

$$
\begin{gathered}
0 \leq \frac{\sum_{j=1}^{J} v_{j m} y_{j m}}{\sum_{i=1}^{I} u_{i m} x_{i m}} \leq 1 ; n=1,2, \ldots, N \\
v_{j m}, \boldsymbol{u}_{i m} \geq 0 ; i=1,2, \ldots I ; j=1,2, \ldots, J
\end{gathered}
$$

\section{Dengan:}

$E$ m adalah efisiensi DMU ke- $m$. $y_{\text {jm }}$ adalah output ke- $j$ untuk DMU ke- $m$. $v_{\mathrm{jm}}$ adalah besarnya bobot output. $x_{\text {im }}$ adalah input ke- $i$ untuk DMU ke- $m$. $u_{\text {im }}$ adalah besarnya bobot input. $y_{\text {jn }}$ dan $x_{\text {in }}$ merupakan output ke- $j$ dan input ke- $i$ untuk masing-masing DMU ke- $n, n=1,2, \ldots, N$. Dan $m$ merupakan bagian dari $n$.

Model DEA pertama kali diperkenalkan oleh Cooper, Charnes dan Rodhes, sehingga model ini lebih dikenal dengan nama Model CCR DEA (Cooper et al., 2006). Pada model ini fungsi pembatas pada tiap DMU memiliki pola yang sama, yang berbeda hanya pada fungsi tujuan atau fungsi DMU yang akan diukur. Model ini dirumuskan sebagai berikut:

$$
\begin{aligned}
& \max z=\sum_{j=1}^{J} v_{j m} y_{j m} \\
& \text { subject to } \\
& \sum_{i=1}^{I} \boldsymbol{u}_{i m} \boldsymbol{x}_{i m} \\
& \sum_{j=1}^{J} v_{j m} y_{j m}-\sum_{i=1}^{I} u_{i m} x_{i m} \leq 0 ; \quad n=1,2, \ldots, N \\
& v_{j m}, \boldsymbol{u}_{j m} \geq 0 ; \quad i=1,2, \ldots, I ; j=1,2, \ldots J
\end{aligned}
$$

Maksimisasi diatas merupakan efisiensi teknis (CCR), $x_{\text {im }}$ adalah banyaknya input tipe ke- $I$ dari DMU ke- $i$ dan $y_{\text {jm }}$ adalah jumlah output tipe ke- $J$ dari DMU ke-j. DMU yang nilai efisensinya kurang dari 1 berarti tidak efisien, sedangkan DMU yang nilai efisiensinya sama dengan 1 berarti efisien.

DMU yang tidak efisien dapat dioptimalkan dengan menggunakan reference set pada DMU itu sendiri, dengan menggunakan formula 2.7 dan 2.8 :

$$
\begin{aligned}
\widehat{x_{o}}= & x_{o}-\Delta x_{o}=\theta^{*} x_{o}-s^{-*} \leq x_{o} \\
& (L . \text { l) } \\
\widehat{y_{o}}= & y_{o}-\Delta y_{o}=\theta^{*} x y_{o}-s^{-*} \leq y_{o}
\end{aligned}
$$

$x_{\mathrm{o}} \geq$ teknis - kumpulan inefisien $=$ kombinasi positif yang diperoleh dari nilai input.

$y_{\mathrm{o}} \geq$ teknis - kumpulan inefisien $=$ kombinasi positif yang diperoleh dari nilai output.

\subsection{Pengujian Hipotesis}

Pengujian hipotesis adalah suatu prosedur yang didasarkan pada bukti sampel dan teori yang digunakan untuk melakukan pembuktian apakah suatu hipotesis merupakan pernyataan yang beralasan atau tidak (Atmaja., 2009).

Salah satu pengujian hipotesis menggunakan uji $t$ dua sampel berpasangan. Pengujian $t$ merupakan pengujian hipotesis yang menggunakan distribusi $t$ sebagai uji statistik (Hasan., 2012). Uji $t$ dua sampel berpasangan bertujuan untuk membandingkan kedua variabel apakah memiliki kesamaan atau tidak. Pengujian ini berupa perbandingan keadan variabel dari dua rata-rata sampel. Secara matematis uji $t$ dirumuskan sebagai berikut: 


$$
t_{\text {hitung }}=\frac{\overline{x_{1}}-\overline{x_{2}}}{\sqrt{\frac{s_{1}}{n_{1}}+\frac{s_{2}}{n_{2}}-2 r\left[\frac{s_{1}}{\sqrt{n_{1}}}\right]+\left[\frac{s_{2}}{\sqrt{n_{2}}}\right]}}
$$

Dengan:

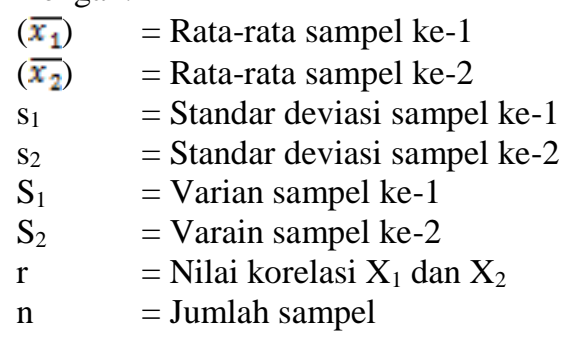

Langkah-langkah pengujian uji $t$ dua sampel berpasangan yaitu :

1. Membuat $\mathrm{H}_{0}$ dan $\mathrm{H}_{1}$ dalam bentuk kalimat.

$\mathrm{H}_{0}$ : Tidak ada perbedaan signifikan

$\mathrm{H}_{1}$ : Terdapat berbedaan signifikan

2. Membuat $\mathrm{H}_{0}$ dan $\mathrm{H}_{1}$ kedalam model statistik

$\mathrm{H}_{0}: \mu 1=\mu 2$

$\mathrm{H}_{1}: \mu 1 \neq \mu 2$

3. Mencari rata-rata, standar deviasi, varian dan korelasi

4. Mencari $t_{\text {hitung }}$ menggunakan rumus 2.9

5. Menentukan kaidah pengujian Tingkat nyata atau level signifikan $\alpha 5 \%$ atau 0,05 .

$\mathrm{dk}=\mathrm{n}_{1}+\mathrm{n}_{2}-2$ (mencari nilai $t_{\text {tabel }}$ dari tabel distribusi $t$ )

Jika $-t_{\text {tabel }} \leq$ thitung $\leq+t_{\text {tabel }}$, maka $\mathrm{H}_{0}$ diterima $\mathrm{H}_{1}$ ditolak.

Jika $-t_{\text {tabel }}>t_{\text {hitung }}$ atau $t_{\text {hitung }}>t_{\text {tabel }}$, maka $\mathrm{H}_{0}$ ditolak $\mathrm{H}_{1}$ diterima.

6. Menarik kesimpulan menerima $\mathrm{H}_{0}$ dan menolak $\mathrm{H}_{1}$, atau Menerima $\mathrm{H}_{1}$ dan menolak $\mathrm{H}_{0}$.

\section{Metodologi}

\subsection{Prosedur Penelitian}

Prosedur penelitian pegukuran efisiensi keuangan daerah digambarkan dalam bentuk bagan seperti pada gambar 1.

Tahap-tahap prosedur penelitian pada gambar 1 adalah sebagai berikut:

1. Studi pustaka dan observasi

Langkah pertama yaitu menetapkan topik penelitian, melakukan kajian teori, mengumpulkan informasi dari kepustakaan dan melakukan pengumpulan data dengan cara mengamati dan mecatat sistematik pada laporan keuangan APBD.

2. Identifikasi masalah
Penentuan permasalahan yang akan diolah dan dianalisis, sejauhmana anggaran belanja daerah tiap program SKPD digunakan secara efisien dan bagaimana mengoptimalkan anggaran ditiap program kegiatan SKPD.

3. Penentuan variabel input dan output

Variabel Input yang digunakan yaitu Pagu belanja barang dan jasa pada Program pelayanan adminstrasi perkantoran dan Output yang digunakan yaitu anggaran belanja pada 8 program kegiatan Pelayanan administrasi perkantoran yaitu:

1) Penyediaan Jasa Surat Menyurat

2) Penyediaan Jasa Pemeliharaan dan Perizinan Kenderaan Dinas/Oprasional

3) Penyediaan Jasa Kebersihan Kantor

4) Penyediaan Alat Tulis Kantor

5) Penyediaan Barang Cetakan dan Penggandaan

6) Penyediaan Bahan Bacaan Dan Peraturan Perundang-Undangan

7) Penyediaan Makanan dan Minuman

8) Rapat-Rapat Koordinasi dan Konsultasi Ke Luar Daerah

4. Implementasi metode

Langkah awal dari tahap implentasi yaitu membuat pola pecahan linear dari variabel input dan output menggunakan model CCR DEA. Untuk melakukan perhitungan efisiensi, maka pecahan linear diubah kedalam bentuk program linear dan dihitung nilai efisensi tiap DMU/ $\theta$, nilai $\lambda$ sebagai refrence set bagi DMU yang belum efisien.

5. Optimalisasi DMU

Langkah berikutnya setelah mengetahui DMU yang efisien dan tidak efisien, yaitu mengoptimalisasi DMU yang belum efisien dengan cara menghitung perubahan nilai variable input dan output.

6. Uji Hipotesis.

Uji hipotesis dimaksudkan untuk melihat akurasi hasil peritungan dengan data pada realisasi anggaran, sehingga bisa ditentukan apakah hasil perhitungan CCR DEA sesuai atau tidak. Dalam penelitian ini menggunakan Uji $t$ Dua Sampel Berpasangan dengan tingkat siginfikan $\alpha 5 \%$ atau 0,05 .

7. Penarikan kesimpulan

Langkah terakhir yaitu menarik kesimpulan dari perhitungan efisiensi keuangan daerah, berupa rekomendasi nilai pagu dan besarnya transaksi tiap program kegiatan SKPD sehingga dapat dikatakan optimal dan efisien. 


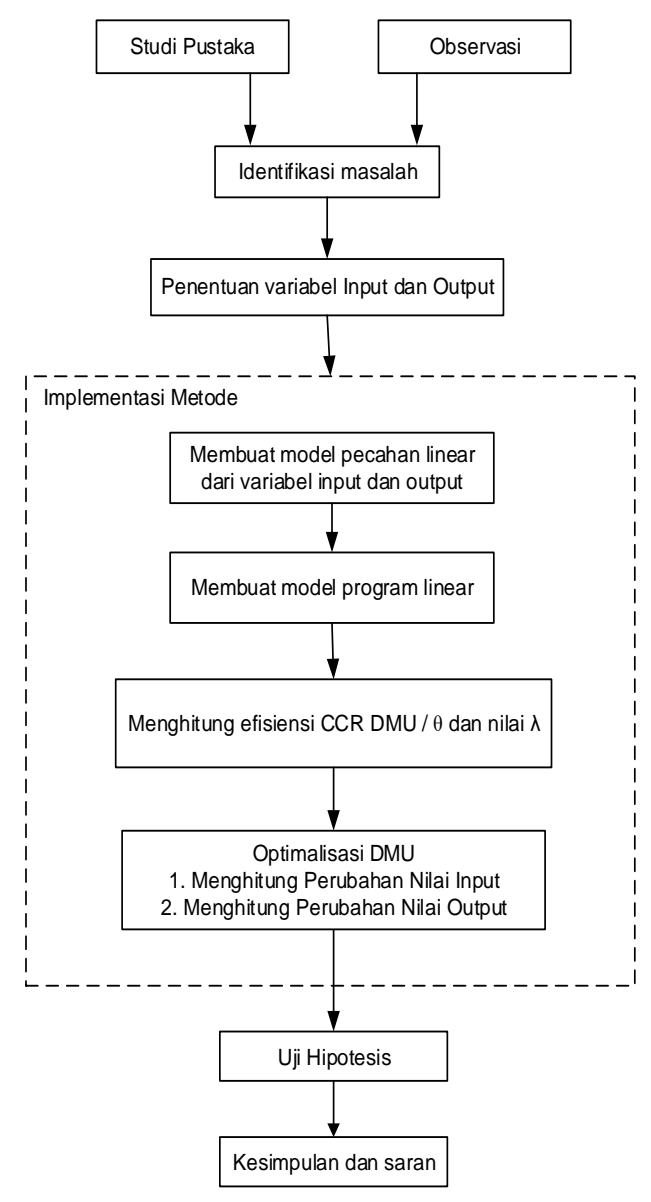

Gambar 1. Prosedur penelitian

\subsection{Kerangka Sistem}

Kerangka sistem pengukuran efisiensi keuangan daerah dapat dilihat pada gambar 2.

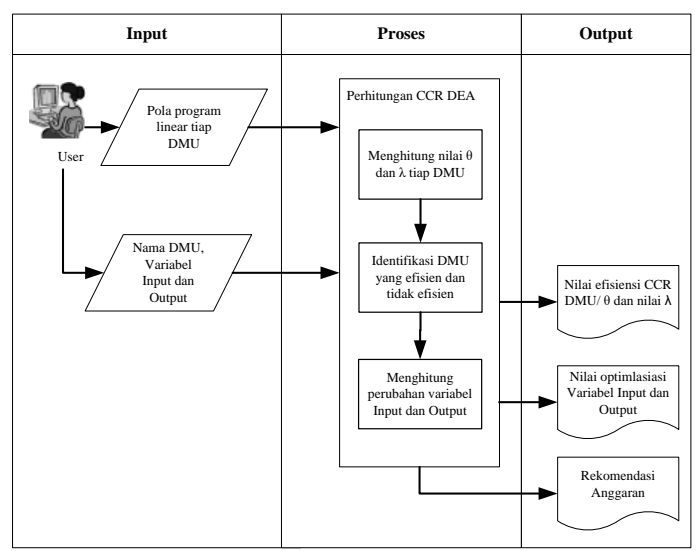

Gambar 2. Kerangka sistem
Secara garis besar kerangka sistem pengukuran efisiensi keuangan daerah pada gambar 3.2 terbagi dalam tiga bagian yaitu:

1. Tahap Input, terdiri dari pengimputan pola program linear tiap DMU, nama DMU dan pengimputan variabel input dan outptu.

2. Tahap Proses. Pada tahap ini dilakukan perhitungan efisiensi tiap DMU dan mengidentifikasi DMU yang efisien dan tidak efisien. Selain itu, pada tahap proses dilakukan perhitungan optimalisasi DMU dengan menghitung perubahan nilai pada variabel input dan output.

3. Tahap Output. Keluaran yang dihasilkan yaitu informasi efisiensi tiap DMU $(\theta)$ dan reference set $(\lambda)$, perubahan nilai input dan output yang optimal tiap DMU serta Rekomendasi Anggaran.

\section{Hasil dan Pembahasan}

Penelitian ini menggunakan 16 DMU dengan 1 variabel input dan 8 variabel output. Data variabel input dan output tiap DMU dapat dilihat pada tabel 1.

Hasil penelitian ditampilkan dalam bentuk dashboard berbasis dekstop sehingga memberikan kemudahan dalam penyajian informasi, selain itu dilakukan validasi antara data hasil perhitungan sistem dengan data pada realisasi anggaran. Hasil dari proses perhitungan efisiensi tiap DMU ditampilkan dalam bentuk informasi seperti pada gambar 3. Sedangkan data input dan output dibuat kedalam bentuk program linear dan menjadi data masukan pada Aplikasi WinQSB untuk dihitung nilai $\theta$ dan $\lambda$ tiap DMU, hasil perhitungan dari 16 DMU dapat dilihat pada tabel 2 . 
Tabel 1. Data variabel input dan output DMU

\begin{tabular}{|c|c|c|c|c|c|c|c|c|c|}
\hline \multirow{2}{*}{$\begin{array}{c}\text { ID } \\
\text { DMU }\end{array}$} & \multirow{2}{*}{ Input } & \multicolumn{8}{|c|}{ Output } \\
\hline & & 1 & 2 & 3 & 4 & 5 & 6 & 7 & 8 \\
\hline DMU01 Pendidikan & 1.106 .600 .000 & 11.800 .000 & 10.000 .000 & 20.400 .000 & 100.000 .000 & 296.375 .000 & 10.000 .000 & 50.000 .000 & 200.000 .000 \\
\hline DMU02 Perencanaan Pembangunan & 741.600 .000 & 5.000 .000 & 5.000 .000 & 9.600 .000 & 81.000 .000 & 10.000 .000 & 10.000 .000 & 28.000 .000 & 250.000 .000 \\
\hline DMU03 Perhubungan Komunkasi dan Informasi & 565.400 .000 & 3.000 .000 & 3.000 .000 & 10.000 .000 & 40.000 .000 & 25.000 .000 & 8.000 .000 & 30.000 .000 & 128.400 .000 \\
\hline DMU04 Lingkungan Hidup & 392.112 .469 & 2.772 .469 & 5.000 .000 & 4.940 .000 & 30.000 .000 & 20.000 .000 & 5.000 .000 & 30.000 .000 & 150.000 .000 \\
\hline DMU05 Pemberdayaan Perempuan Dan Perlindungan Anak & 267.289 .637 & 1.500 .000 & 2.000 .000 & 3.600 .000 & 20.000 .000 & 8.000 .000 & 5.000 .000 & 16.489 .637 & 80.000 .000 \\
\hline DMU06 Ketenagakerjaan & 532.846 .390 & 5.000 .000 & 5.000 .000 & 6.000 .000 & 50.000 .000 & 16.000 .000 & 8.400 .000 & 25.200 .000 & 149.946 .390 \\
\hline DMU07 Koperasi Dan Usaha Kecil Menengah & 300.048 .963 & 2.500 .000 & 10.000 .000 & 2.198 .963 & 30.000 .000 & 20.000 .000 & 4.000 .000 & 30.000 .000 & 85.000 .000 \\
\hline DMU08 Pariwisata Kebudayaan dan Olahraga & 320.560 .000 & 5.000 .000 & 2.000 .000 & 1.460 .000 & 25.000 .000 & 10.000 .000 & 5.000 .000 & 12.500 .000 & 75.000 .000 \\
\hline DMU09 Kesatuan Bangsa Dan Politik Dalam Negeri & 229.100 .000 & 5.000 .000 & 5.000 .000 & 2.800 .000 & 30.000 .000 & 6.000 .000 & 5.000 .000 & 15.000 .000 & 112.400 .000 \\
\hline DMU10 Inspektorat Daerah & 208.047 .489 & 2.897 .489 & 1.750 .000 & 2.800 .000 & 24.000 .000 & 5.000 .000 & 3.200 .000 & 15.000 .000 & 75.000 .000 \\
\hline DMU11 Pelayanan Perizinan Terpadu & 225.106 .390 & 3.000 .000 & 500.000 & 6.000 .000 & 20.000 .000 & 25.000 .000 & 2.000 .000 & 15.000 .000 & 50.000 .000 \\
\hline DMU12 Ketahanan Pangan & 397.800 .000 & 10.000 .000 & 5.000 .000 & 7.600 .000 & 35.000 .000 & 15.000 .000 & 8.000 .000 & 20.000 .000 & 150.000 .000 \\
\hline DMU13 Pemberdayaan Masyarakat dan Desa & 393.600 .000 & 5.000 .000 & 2.500 .000 & 6.000 .000 & 15.000 .000 & 10.000 .000 & 7.000 .000 & 25.000 .000 & 125.000 .000 \\
\hline DMU14 Perkebunan dan Kehutanan & 382.100 .000 & 7.500 .000 & 5.000 .000 & 6.000 .000 & 30.000 .000 & 15.000 .000 & 10.000 .000 & 18.000 .000 & 148.500 .000 \\
\hline DMU15 Pertambangan dan Energi & 413.175 .823 & 5.000 .000 & 2.000 .000 & 6.000 .000 & 30.000 .000 & 10.000 .000 & 5.000 .000 & 20.000 .000 & 150.000 .000 \\
\hline DMU16 Kelautan Dan Perikanan & 316.900 .000 & 7.500 .000 & 2.500 .000 & 6.000 .000 & 45.000 .000 & 10.000 .000 & 7.500 .000 & 15.000 .000 & 104.000 .000 \\
\hline
\end{tabular}

\section{Keterangan:}

Input : Pagu Belanja Barang dan Jasa

Output :

1. Penyediaan Jasa Surat Menyurat

2. Penyediaan Jasa Pemeliharaan dan Perizinan Kenderaan Dinas/Oprasional

3. Penyediaan Jasa Kebersihan Kantor

4. Penyediaan Alat Tulis Kantor

5. Penyediaan Barang Cetakan dan Penggandaan

6. Penyediaan Bahan Bacaan Dan Peraturan Perundang-Undangan

7. Penyediaan Makanan dan Minuman

8. Rapat-Rapat Koordinasi dan Konsultasi Ke Luar Daerah

Tabel 2. Hasil perhitungan LPWinQSB

\begin{tabular}{|c|c|c|c|c|c|c|c|c|c|c|c|c|c|c|c|c|c|c|}
\hline ID DMU & $\mathrm{CCR} / \theta$ & $\lambda 1$ & $\lambda 2$ & $\lambda 3$ & $\lambda 4$ & $\lambda 5$ & $\lambda 6$ & $\lambda 7$ & $\lambda 8$ & $\lambda 9$ & $\lambda 10$ & $\lambda 11$ & $\lambda 12$ & $\lambda 13$ & $\lambda 14$ & $\lambda 15$ & $\lambda 16$ & Reference Set \\
\hline DMU01 & 1 & 1 & 0 & 0 & 0 & 0 & 0 & 0 & 0 & 0 & 0 & 0 & 0 & 0 & 0 & 0 & 0 & 1 \\
\hline DMU02 & 0,8221 & 0 & 0 & 0 & 0 & 0 & 0 & 0 & 0 & 1,4442 & 0 & 0,1599 & 0 & 0 & 0 & 0 & 0,7661 & $9,11,16$ \\
\hline DMU03 & 0,8602 & 0 & 0 & 0 & 0 & 0 & 0 & 0,204 & 0 & 0 & 0 & 0,8646 & 0 & 0 & 0 & 0 & 0,7273 & $7,11,16$ \\
\hline DMU04 & 0,9945 & 0 & 0 & 0 & 0 & 0 & 0 & 0,4253 & 0 & 0,9035 & 0 & 0,2459 & 0 & 0 & 0 & 0 & 0 & $7,9,11$ \\
\hline DMU05 & 0,9299 & 0 & 0 & 0 & 0 & 0 & 0 & 0,2878 & 0 & 0,0436 & 0 & 0 & 0 & 0 & 0,0297 & 0 & 0,4446 & $7,9,14,16$ \\
\hline DMU06 & 0,7541 & 0,0003 & 0 & 0 & 0 & 0 & 0 & 0,2214 & 0 & 0,5675 & 0 & 0,0762 & 0 & 0 & 0,0784 & 0 & 0,4983 & $1,7,9,11,14,16$ \\
\hline DMU07 & 1 & 0 & 0 & 0 & 0 & 0 & 0 & 1 & 0 & 0 & 0 & 0 & 0 & 0 & 0 & 0 & 0 & 7 \\
\hline DMU08 & 0,7088 & 0,0127 & 0 & 0 & 0 & 0 & 0 & 0 & 0 & 0,4273 & 0 & 0 & 0 & 0 & 0,0092 & 0 & 0,3526 & $1,9,14,16$ \\
\hline DMU09 & 1 & 0 & 0 & 0 & 0 & 0 & 0 & 0 & 0 & 1 & 0 & 0 & 0 & 0 & 0 & 0 & 0 & 9 \\
\hline DMU10 & 0,9822 & 0 & 0 & 0 & 0 & 0 & 0 & 0,2065 & 0 & 0,3676 & 0 & 0,1239 & 0 & 0 & 0 & 0 & 0,0956 & $7,9,11,16$ \\
\hline DMU11 & 1 & 0 & 0 & 0 & 0 & 0 & 0 & 0 & 0 & 0 & 0 & 1 & 0 & 0 & 0 & 0 & 0 & 11 \\
\hline DMU12 & 1 & 0 & 0 & 0 & 0 & 0 & 0 & 0 & 0 & 0 & 0 & 0 & 1 & 0 & 0 & 0 & 0 & 12 \\
\hline DMU13 & 0,9553 & 0 & 0 & 0 & 0 & 0 & 0 & 0,3064 & 0 & 0,3115 & 0 & 0,2456 & 0 & 0 & 0 & 0 & 0,4968 & $7,9,11,16$ \\
\hline DMU14 & 1 & 0 & 0 & 0 & 0 & 0 & 0 & 0 & 0 & 0 & 0 & 0 & 0 & 0 & 1 & 0 & 0 & 14 \\
\hline DMU15 & 0,8705 & 0 & 0 & 0 & 0 & 0 & 0 & 0 & 0 & 0,5527 & 0 & 0 & 0,5859 & 0 & 0 & 0 & 0 & 9,12 \\
\hline DMU16 & 1 & 0 & 0 & 0 & 0 & 0 & 0 & 0 & 0 & 0 & 0 & 0 & 0 & 0 & 0 & 0 & 1 & 16 \\
\hline
\end{tabular}

Hasil perhitungan efisiensi menunjukan terdapat 7 DMU yang efisien yaitu Pendidikan, Koperasi Dan Usaha Kecil Menengah, Kesatuan Bangsa Dan Politik Dalam Negeri, Pelayanan Perizinan Terpadu, Ketahanan Pangan, Perkebunan dan Kehutanan dan Kelautan dan Perikanan.

DMU yang tidak efisien sebanyak 9 DMU diamana DMU08 atau SKPD Pariwisata Kebudayaan dan Olahraga memiliki nilai CCR terendah yaitu 0,7088. Sedangkan DMU yang memiliki nilai mendekati efisien yaitu DMU04 atau SKPD Lingkungan Hidup dengan nilai 0,9945. Secara grafik nilai hasil perhitungan efisiensi Model CCR DEA disajikan pada gambar 3. 


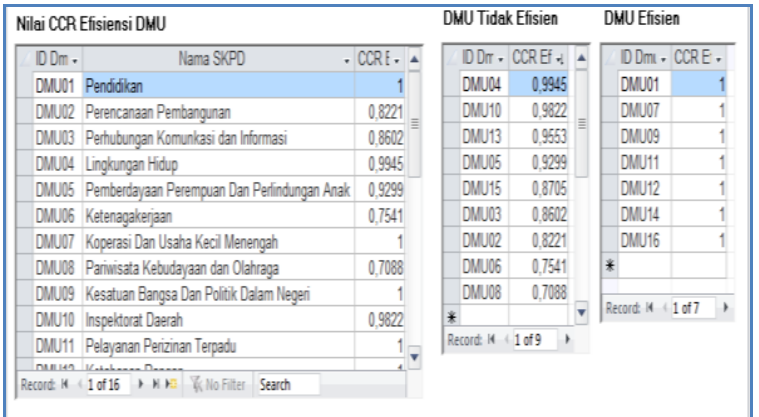

Gambar 3. Nilai CCR Efsiensi DMU

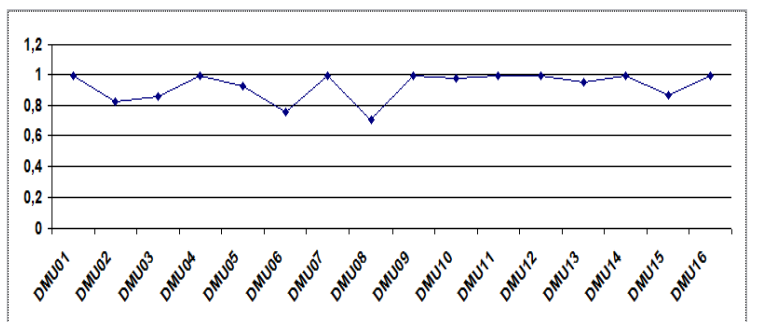

Gambar 4. Grafik nilai CCR Efsiensi DMU

Perhitungan optimalisasi nilai pada varaiabel input dan output menghasilkan rekomendasi anggaran seperti pada gambar 5 ..

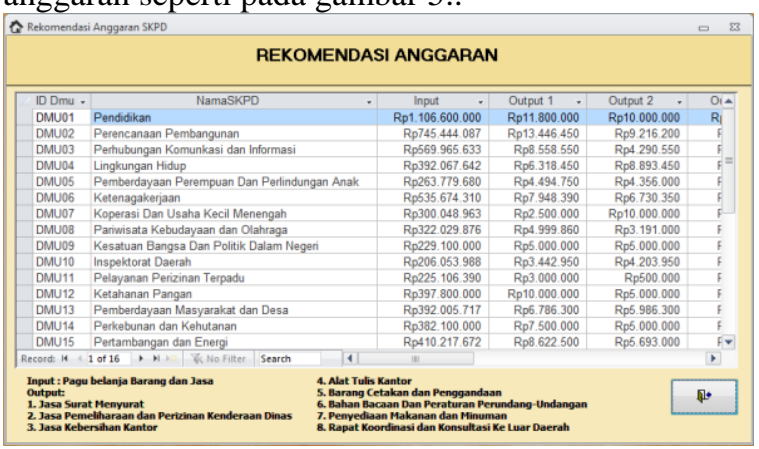

Gambar 5. Rekomendasi anggaran
Rekomendasi anggaran terdiri dari nilai pagu atau variabel input dan rancangan anggaran kedelapan program atau variabel output. Hasil dari rekomendasi anggaran ini merupakan tahap akhir dari pengukuran efisiensi keuangan daerah menggunakan Model CCR DEA.

Proses validasi dilakukan melalui pengujian hipotesis uji $t$ dua sampel berpasangan (Paired Sample $t$-Test) dengan membandingkan hasil perhitungan sistem CCR DEA pada rekomendasi anggaran dengan data pada realisasi anggaran.

Perbandingan dilakuan pada tiap variabel baik input maupun output. Jumlah sampel yang digunakan sebanyak 16 yaitu jumlah DMU/SKPD. Tingkat nyata atau level of significance yang digunakan yaitu $\alpha 5 \%$ atau 0,05 . Adapun kaidah pengujiannya adalah sebagai berikut:

$\mathrm{dk}=\mathrm{n}_{1}+\mathrm{n}_{2}-2=16+16-2=30$.

$t_{\text {tabel }}$ untuk $\alpha 0,05$ pada baris ke $30=2,042$.

Rumus Hipotesa:

$\mathrm{H}_{0}$ Sesuai Harapan $-2,042 \leq t_{\text {hitung }} \leq 2,042$

$\mathrm{H}_{1}$ Tidak Sesuai Harapan $t_{\text {hitung }}$

$<-2,042$ atau $t_{\text {hitung }}<2,042$.

Jumlah pengujian sebanyak 9 terdiri dari 1 pengujian nilai input dan 8 pengujian output. Hasil dari pengujian dapat dilihat pada tabel 3 .

Hasil uji $t$ pada tabel 3 menujukan semua hasil pengujian memenuhi hioptesis $-2,042 \leq t_{\text {hitung }} \leq$ 2,042, sehingga disimpulkan pengukuran efiseinsi keuangan daerah menggunakan model CCR DEA sesuai harapan.

Tabel 3. Hasil uji $t$ pada variabel input dan output

\begin{tabular}{|c|c|c|c|c|c|c|c|c|c|}
\hline \multirow{2}{*}{$\begin{array}{c}\text { Nama } \\
\text { Pengujian }\end{array}$} & \multicolumn{2}{|c|}{ Rata-Rata } & \multicolumn{2}{|c|}{ Standard Deviasi } & \multicolumn{2}{|c|}{ Varian } & \multirow{2}{*}{ Korelasi } & \multirow{2}{*}{$t_{\text {Hitung }}$} & \multirow{2}{*}{ Keterangan } \\
\hline & $\mathrm{X}_{1}$ & $\mathrm{X}_{2}$ & $\mathrm{~s}_{1}$ & $\mathrm{~s}_{2}$ & $\mathrm{~S}_{1}$ & $\mathrm{~S}_{2}$ & & & \\
\hline Input & $424.517 .947,56$ & $457.247 .474,69$ & $229.408 .270,40$ & $223.961 .550,38$ & $52.628 .154 .526 .213 .300,00$ & $50.158 .776 .048 .169 .200,00$ & 0,98 & $-0,408$ & Ho \\
\hline Output 1 & $5.154 .372,38$ & $4.935 .622,38$ & $2.819 .469,85$ & $2.760 .508,83$ & 7.949.410.238.564,78 & 7.620.409.013.564,78 & 0,87 & 0,222 & Ho \\
\hline Output 2 & $4.140 .625,00$ & $3.984 .375,00$ & $2.738 .565,24$ & $2.714 .879,91$ & 7.499.739.583.333,33 & $7.370 .572 .916 .666,67$ & 0,92 & 0,162 & Ho \\
\hline Output 3 & $6.337 .435,19$ & $6.725 .000,00$ & $4.468 .267,99$ & $4.401 .402,81$ & $19.965 .418 .812 .210,60$ & $19.372 .346 .666 .666,70$ & 0,98 & $-0,247$ & Ho \\
\hline Output 4 & $37.812 .500,00$ & $37.812 .500,00$ & $22.745 .603,97$ & $22.745 .603,97$ & $517.362 .500 .000 .000,00$ & $517.362 .500 .000 .000,00$ & 1 & 0 & Ho \\
\hline Output 5 & $31.335 .937,50$ & $31.773 .437,50$ & $70.949 .787,39$ & $70.802 .692,67$ & $5.033 .872 .330 .729 .170,00$ & 5.013.021.289.062.500,00 & 1 & $-0,017$ & Ho \\
\hline Output 6 & $6.443 .750,00$ & $6.600 .000,00$ & $2.512 .626,45$ & $2.656 .313,23$ & 6.313.291.666.666,67 & 7.056.000.000.000,00 & 0,97 & $-0,171$ & Ho \\
\hline Output 7 & $22.824 .352,31$ & 24.074.352,31 & $9.525 .338,81$ & $9.391 .510,71$ & $90.732 .079 .508 .652,10$ & $88.200 .473 .341 .985,50$ & 0,92 & $-0,374$ & Ho \\
\hline Output 8 & $127.077 .899,38$ & $147.868 .750,00$ & $51.050 .177,75$ & $51.230 .416,99$ & 2.606.120.648.068.670,00 & 2.624.555.625.000.000,00 & 0,82 & $-1,150$ & Ho \\
\hline
\end{tabular}

Ho : Sesuai Harapan

H1 : Tidak Sesuai Harapan 


\section{Kesimpulan}

Penelitian menghasilkan kesimpulan, nilai efisiensi relatif dari DMU dengan karakterisitik single input dan multiple output dapat dihitung menggunakan Model CCR DEA, dengan hasil pengujian pada 9 variabel terdiri dari 1 variabel input dan 8 variabel output memenuhi hipotesis Ho -2,042 $\leq$ thitung $\leq 2,042$, sehingga Model CCR DEA dapat digunakan sebagai metode pengukuran efisiensi keuangan daerah dan dapat menghasilkan rekomendasi rancangan anggaran untuk periode selanjutnya.

\section{Daftar Pustaka}

Atmaja, LS., 2009. Statistika Untuk Bisnis dan Ekonomi, Andi Offset, Yogyakarta.

Charles, V., Zegarra, LF., 2014. Measuring regional competitiveness through data envelopment analysis: a peruvian case, Expert Systems with Applications 41, 5371-5381.

Charnes, A., Cooper, W.W., Rhodes, E., 1978. Measuring the efficiency of decision making units, European Journal of Operational Research 2, 429-444.

Cooper, WW., Seiford, LM., Tone, K., 2006. Introduction Data Envelopment Analysis and Its Uses With DEA-Solver Software and Refrences, Springer, United States of America.

Halim, A., 2007. Akuntansi sektor Publik Akuntnasi Keuangan Daerah Edisi 3, Salemba Empat, Jakarta.

Halim, A., 2014. Manajemen Keuangan Sektor Publik Problematika Penerimaan Dan Pengeluaran Pemerintah (Anggaran Pendapatan dan Belanja Negara/Daerah), Salemba Empat, Jakarta.

Hanushek, E., Lockheed, ME., 1994. Concepts of Educationa Efficiency and Effectivenes, HROWP.

Hasan, MI., 2012. Pokok-Pokok Materi Statistik 2 (Statistik Infrensif), Bumi Aksara, Jakarta.
Lee, H., Kim, C., 2012, A DEA-SERVQUAL approach to measurement and benchmarking of service quality, Procedia - Social and Behavioral Sciences, 40, $756-762$.

Ramanthan, R., 2004. An Introduction to Data Envelopment Analysis : A Tool For Performance Measurement, Sage Publications Inc, New Delhi.

Republik Indonesia., 2005. Peraturan Pemerintah Nomor 58 Tahun 2005 Tentang Pengolahan Keuangan Daerah, Jakarta.

Rosman, R., Wahab NA., Zainol Z., 2014. Efficiency of Islamic banks during the financial crisis: An analysis of Middle Eastern and Asian Countries, Pacific-Basin Finance Journal 28, 76-90.

Rusydiana, AS., Tim SMART Consulting., 2013. Mengukur Tingkat Efisiensi dengan Data Envelopment Analysis, SMART Publishing, Bogor.

Siregar, Y., 2001. Akuntansi Pemerintahan dengan Sistem Dana Edisi ke 3, YKPN. Yogyakarta.

Sumenge, AS., 2013. Analisis Efektifitas dan Efisiensi Pelaksanaan Anggaran Belanja Badan Perencanaan Pembangunan Daerah (BAPPEDA) Minahasa Selatan, Jurnal EMBA 1 (3), 74-81.

Syamsu, I., 2007. Efisiensi, Sistem dan Prosedur Kerja, Bumi Aksara, Jakarta.

Taylor, BW., 2014. Sains Manajemen Introduction to Management Science, Penerbit Salemba Empat. Jakarta.

Tsai, PF., Molinero, CM., 2002. A variable returns to scale data envelopment analysis model for the joint determination of efficiencies with an example of the UK Health service, European Journal of Operational Research 141 21-38.

Utama, AHM., Bahauddin, A., Ferdinant, PF., 2013. Pengukuran Efisiensi Produksi dengan Metode Data Envelopement Analysis di Divisi Wire Rod Mill, JTI 1 233-238.

Zhu, J., Cooka WD., Tone K., 2014. Data Envelopment Analysis: Prior to Choosing a Model, Omega 44, 1-4. 